\title{
“Telling Masculine Tales": Tracing My Embodied Experience as a Psychiatric Ward Security Guard through Ethnographic Narrative Writing
}

\author{
Matthew S. Johnston \\ Department of Sociology, University of Victoria, Victoria, Canada \\ Email: mattjohnstonca@gmail.com
}

Received 25 February 2014; revised 26 March 2014; accepted 4 April 2014

Copyright (C) 2014 by author and Scientific Research Publishing Inc.

This work is licensed under the Creative Commons Attribution International License (CC BY). http://creativecommons.org/licenses/by/4.0/

\section{(c) (i) Open Access}

\begin{abstract}
This article unfolds the culture of hyper-masculinity I witnessed and ultimately rejected during my sixteen-month career working as a private security officer in an Ottawa hospital. I draw on two ethnographic narratives to "distribute", in Rancièrian terms, the embodied and emotional experiences that accompanied my struggles to achieve hegemonic masculine status, and resist military-like hierarchies inside an institutional setting. Such a creative methodological exercise allows researchers to freely explore their delicate, complex and messy feelings that may otherwise be ethically suppressed or co-opted through less corporeal representations of academic writing. Moreover, by revealing the sensitive and coercive interactions that steered my gendered relationships with psychiatric patients, ward nurses and other security agents, I demonstrate how embodied research can transform our uncritical heteronormative positions on masculinity and violence, as well as contest the unequal, gendered and medicalized judgments that are imposed on incarcerated mental health patients.
\end{abstract}

\section{Keywords}

Creative Methodologies; Autoethnography; Masculinities; Private Security Officers; Psychiatric Patients; Emotions

I don't think it'll ever matter what I do in life or what direction I go. Whether I don't paint or... what it is. It's always going to come back into my life. It's always going to creep back in. You know, I went to the opposite side of the spectrum and was in the military and was...you know, very hard and angry and...very 
aggressive. And it didn't matter, six years or whatever...it came back out, that creative side. You can never crush it.

I said to myself what would I rather do? Right, I have a choice. It's either shoot behind a gun or shoot behind a camera. One creates and one destroys.

Former psychiatric ward security officers ${ }^{1}$

\section{Introduction}

After a long phone conversation with my mother during the early morning of 8 March 2010, I made one final call to a hospital in Ottawa to resign my position as a security guard. That very night I witnessed, for the last time, a woman forced to lie on her stomach on a hospital gurney as a nurse prepared a chemical sedative. With the help of several security officers, personal care assistants, and nursing staff members, we restrained each of the woman's limbs so that she could receive an injection in what I later remembered as "the final image in a collection of images I have of bare-asses” (Johnston \& Kilty, 2014). This incident represented the intrinsic shift in attitude I experienced towards the role of security in reinforcing the hospital's authority to remove the autonomy and integrity of those we deem mentally unfit. I was no longer willing to compromise the bodily and emotional integrity of patients I encountered through overt and discreet demonstrations of authority, physicality, control, intimidation, discrimination, legitimation and ambivalence towards feminine, subordinated masculine and queer gender identities - the documented characteristics of hegemonic masculinity ${ }^{2}$ in many security (Johnston \& Kilty, 2014; Monaghan, 2002; Rigakos, 2002; Thumala, Goold, \& Loader, 2011; Walby, 2009), policing (Fielding, 1984; Moore, 1999; Prokos \& Padavic, 2002; Rabe-Hemp, 2009), prison (Acker, 1990, 1992; Britton, 1997, 2003; Evans \& Wallace, 2008; Jewkes, 2005) and military like institutions ${ }^{3}$ (Duncanson, 2009; Johnson, 2010; Shefer \& Mankayi, 2007). Instead, I sought to create change, that is to say, improve the ways in which we care for and express compassion towards vulnerable patients whom we label and stigmatize as "dangerous" (Federman, 2012), and in many cases, incarcerate without their permission in order to "preserve" their physical, mental and emotional well being ${ }^{4}$.

Laying to rest my security uniform, belt, and tactical equipment meant encountering a sense of regret towards my old way of doing gender (West \& Zimmerman, 1987). I felt compelled to reconcile my own hurt, anguish and remorse, as well as the pain, restriction and coercion I helped perpetrate against emergency and long-term psychiatric patients. I yearned to capture and re-experience the moments of gender transformation, awakening and agency that allowed me to "come undone" (Butler, 2004: p. 19); re-define the gendered politics, discourses and expressions of self that make up my identity as a man. Of course, to re-enter, re-interpret, and reconcile elements of my past, or what Avery Gordon (2008: p. xvi) describes as a haunting “domain of turmoil and trouble...that moment (of however long duration) when things are not in their assigned places... when disturbed feelings cannot be put away”, impelled me to engage with a methodology that was new and creative (Denzin, 2003: p. 118), maintained fluid degrees of reflexivity (Mauthner \& Doucet ,2003; Walby, 2007), and could grapple with the complex, messy and embodied constructions of truths and dynamics of power that help steer and produce critical feminist research (Inckle, 2010: p. 28). A cathartic, yet scholarly practice, I hoped, would release my own tensions and sorrow, as well as inspire other artistic, academic and institutional audiences to

\footnotetext{
${ }^{1}$ These passages were extracted from the interview transcripts of two of my former colleagues. All of the interviews (8 in total) from this MA-level research were conducted in person after I received ethics clearance from the University of Ottawa's Social Sciences and Humanities Research Ethics Board.

${ }^{2}$ Hegemonic masculinity is established as a configuration of practices that subordinate (rather than eliminate) less dominant masculinities in order to preserve the dominant position of men and maleness over women and relegated men (Connell, 1995; Connell \& Messerschmidt, 2005). As Connell (1987: p. 186) argues, the process of achieving alpha masculine status involves the systematic suppression and subordination of alternative masculinities and, most importantly, sexualities that transgress heteronormative demarcations.

${ }^{3}$ On June 07, 2013, CFB Edmonton became the first military base in Canada to officially hoist the Pride flag, which is the universal symbol for, among other identities and sexualities, lesbian, gay, bisexual, transgender, queer, and gender-variant persons/communities across the globe (The Huffington Post Alberta, 2013). This historic event signals an intrinsic shift in cultural attitudes towards persons and communities who do not live up to the heteronormative expectations of what it means to present and live as a woman, man or other gender.

${ }^{4}$ As per the Canadian Ontario Mental Health Act (1990), Form One refers to an assessment order summoned by an attending physician, which authorizes psychiatric facilities to involuntarily admit "unstable" patients for an initial 72-hour observation period when they are deemed by a physician to be a "dangerous" threat to themselves or others. Once this holding period has expired, the psychiatric facility may continue to hold the patient on subsequent Forms until a psychiatrist or attending physician has deemed the said person mentally stable. Interestingly, physicians hold the responsibility of assessing a patient's dangerousness even though there is no established scientific measurement or definition of “dangerous” (see Federman, 2012).
} 
become personally and politically invested in "varying degrees of social action” (Guba \& Lincoln, 2005: p. 268) that endeavour to transform unjust psychiatric practices and hospital security measures. I asked myself, can a rallying cry for justice and embodied gender politics of this nature help me come in touch with the inner voice in my body that knows and can express the haunting memories, feelings and emotions that still stir from time to time? If so, how can I reproduce my past in a way that is trustworthy, reliable, scientific, yet still transgresses the epistemological and creative boundaries between science and art, politics and aesthetics (Rancière, 2006), truth and fiction (Inckle, 2010)?

Keeping these reflexive and perhaps ambitious dispositions in mind, the goal of this article is to trace my non-linear transformation from a masculine-conforming security agent to a critical researcher who now calls for the decay of hegemonic masculine discourses and practices within medicalized establishments. The ethnographic narratives express my positions and experiences in a way that, as Rancière (2006: p. 14) imagines, "destory(s) all of the hierarchies of representation" that distinguish affects and emotions from "legitimate" knowledge $^{5}$. I describe without restriction how corporeal experience led me from a heteronormative understanding of the everyday world to a more complicated, irresolvable, flexible, "less oppressive" (Lather, 1991: p. 95) understanding of my own gender identity. In so doing, these ethnographic narratives seek to disrupt the hierarchies of intelligence and less emotional forms of expression and discourse that continue to reproduce and exacerbate the coercive treatment, pathological labeling and depriving conditions of medically incarcerated persons whom we come to accept as mentally "unsound" (see also Holmes, Jacob, \& Perron, forthcoming; Szasz, 2010). By adopting a critical, reflexive and embodied approach to ethnographic narrative writing, and by trying to live up to Cedric Robinson's call for politically engaged persons to "side with the excluded and the repressed, to develop insights gained in confrontation with injustice, to nourish cultures of resistance...to reach the full breadth of our human potentialities" (cited in Morse, 1999), I endeavour to strengthen the audibility and passion of my critical call to disentangle and transform the coercive and hegemonic masculine processes that are fundamental to the psychiatric ward security guard's gendered performances, achievements, failures and coercions.

This paper is divided into four parts. First, I explore how the creative methodologies employed throughout Kay Inckle's (2007, 2010) and Avery Gordon's (2008) autoethnographic work—all of which adopt fictional voices and representations-are situated within a critical feminist epistemology. Second, I discuss how French philosopher Jacques Rancière's (2006) notion of intellectual equality establishes the need for distributions of emotions and corporeal experiences in academic writing in order to transgress the positivist hierarchies (i.e. psychiatric and medical) that disenable reflexivity and voice from gaining political significance in the on-going debates and legislation that permit psychiatric facilities to restrain, sedate, seclude and restrict the social and physical autonomy of involuntarily-committed mental health patients (Ashcraft \& Anthony, 2010; Federman, 2012; Liberman, 2006; Ontario Mental Health Act, 2010). Once I have established this methodological and theoretical framework, I present the two ethnographic narratives or "glimpses" of the psychiatric ward, before departing on a brief discussion of how past events, traumas and reflexive ethnographic writing can transform our heteronormative judgments of persons we come to understand as mentally unwell.

\section{Reflections on Fictional/Non-Fictional Representations of Self}

Some of us say we write fiction, others swear their work is a product of fact, and perhaps a great deal of researchers elect to choose their words carefully when making metaphysical claims about the concrete "realness" of the words, images and experiences that shape our lives, and those of the participants. In her recent work, Kay Inckle $(2007,2010)$ demonstrates how fictional voices and representations can produce embodied, reflexive, and critically feminist subjects. Avery Gordon (2008: p. 11) likewise asserts how "the real itself and its ethnographic or sociological representations are also fictions, albeit powerful ones that we do not experience as fictional, but as true”. Creative methodologies of these kinds may overcome ethical tensions that surface for researchers who need permission from their Research Ethics Boards (REBs) to retrospectively write about their sensitive and vulnerable experiences in the field (Haggerty, 2004; Herrera, 1999; Holland, 2007; Librett \& Perrone, 2010; Schlosser, 2008). Quite open to experimentation with narration, metaphor, flashbacks and other artistic literary

${ }^{5}$ On a personal note, I have been writing poetry since 2005, and playing guitar since 2011. Until I began writing the ethnographic narratives, I had always understood my artistic and academic worlds as utterly separable. In doing this research, I was surprised at how naturally and comfortably the ethnographic narratives fit within - not in between - the voices of the security guards whom I interviewed. With the incorporation of these ethnographic narratives, it seemed that our voices had become distinct, yet reached an "intellectually equal" volume (Rancière, 2003: p. 198), with one united critical mission to transform the unjust practices of the institution we (in some cases, used to) work at. 
devices, ethnographic fiction writing in particular allows Inckle and Gordon to capture both imaginatively and critically the nuanced, contradictory, complex, everyday experiences and realities of women who engage in self-injurious practices, and persons who experience haunting. In other words, these empirically based short stories hold the capacity to draw on real events and real persons, but are crafted, modified, and re-written into "carefully crafted themed vignettes, each of which deals with a specific issue" (Inckle, 2010: p. 37). As Inckle (2010: pp. 38-39) summarizes, creative methodologies of this kind transgress the knowledge hierarchies that limit, approve and disapprove of classified modes of production-particularly those that engage in a deep partitioning that separates scientific, legitimate knowledges from the often-feminized affects and emotions that are inherent to "gendered embodiment".

Ethnographic fictions offered an answer...to the struggle of how to bring lived experience into the academic realm...[and] offered an ideal strategy for conveying the "embodied tale", not only of the complexity, contradictions, pains, pleasures and politics of gendered embodiment and body-marking practices, but also of how we come to make and privilege certain kinds of knowledge.

Some critics contend that fictional accounts of real events and multiple lives are limited by the capacity of self-knowledge and representation (Phillips \& Earle, 2010: p. 362). Yet since it is difficult, if not impossible, to ever "truly" know what lies beyond the narrated subject (Doucet \& Mauthner, 2008), or the picture of ourselves that is produced and discursively disseminated through the stories we tell to others in hopes that they may come to a better (albeit incomplete) comprehension of our identities, I tread on thin ice to assume that a work of fiction is, by nature, not a work of truth, or at the very least, of some truth. I am likewise skeptical of the social researcher who claims to have stumbled upon absolute reality, yet forgets to make explicit the reflexive, subjective impulses or callings that guided them to, and shaped their findings. Gordon (2008: p. xvi) delineates how the paranormal, surreal and unfamiliar experiences of the world can provide us with insight into the paradoxical and complicated landscape in which we attempt to re-tell, re-explain and re-live the transformative moments of our lives.

Haunting was the language and the experiential modality by which I tried to reach an understanding of the meeting of force and meaning, because haunting is one way in which abusive systems of power make themselves known and their impacts felt in everyday life...I used the term haunting to describe those singular yet repetitive instances when home becomes unfamiliar, when your bearings on the world lose direction, when the over-and-done-with comes alive, when what's been in your blind spot comes into view.

For Gordon, our engagement with a fictional voice reveals insight into our other-worldly thoughts and realities, and stresses the importance of incorporating the human and subjective dimensions of the research process into the analysis, so that our corporeal experiences are translated into sensory, political and compassionate "ways of doing and making” (Rancière, 2006: p. 13). As critical feminist researchers we must find a language to do justice to the ongoing gendered pains, deprivations, violence, stigma, and social structures that shape and culturally deteriorate our institutions. But in this very pursuit for social justice, we must also understand that there are mysteries behind every story, and ineffable layers beyond every word we share to re-call our moments of lived experience, suffering, reconciliation and transformation: “...even those who live in the most dire circumstances possess a complex and oftentimes contradictory humanity and subjectivity that is never adequately glimpsed by viewing them as victims or, on the other hand, as superhuman agents” (Gordon, 2008: p. 4). As I began to write about my own experience working as a security guard in a local hospital, I knew that the intense emotions and politics I felt come undone as I recalled the lives of both myself and my former security colleagues were inspired by the "fact" that they all, in some capacity during the brief or seemingly infinite moments when I know and remember them, expressed to me a desire to witness the end of gendered healthcare violence, discrimination, subordination and coercion against mental health patients and themselves (see also Holmes, Rudge, Perron, \& St-Pierre, 2012; Mason, 2006). In these moments of self-examination, pity, and trauma, I remember the words of renowned cultural criminologist and ethnographer Jeff Ferrell (1998: p. 24). He reminds us that if we are to maintain our distance from methodologies that sterilize the felt emotion of experience and exempt persons from reflexivity, we must

reintroduce the humanity of the research into the research process and make a case for critical, reflexive, autobiographical accounts and understandings—-for profound self disclosures and openness to the "subjec- 
tive experience of doing research”-as part of the field research process.

We are all human beings, and thus we should make it our goal to ensure that all human life and social relations are depicted as such. This of course may be a difficult quest to complete as we navigate our way through our barriers, haunting memories, and difficulties coming to terms with the past. Indeed, my corporeal discoveries, frustrations, and lived traumas throughout my work experience as a private security officer assure me that the embodied experience of qualitative research is as much emotional as it is scholarly laborious and cumbersome (Dickson-Swift, James, Kippen, \& Liamputtong, 2009). I recognize that my former involvement in the restraint and coercion of psychiatric patients drives my motivation to petition for the social refuge of medically institutionalized persons. Yet this is a vision and ambition we as critical feminist scholars share (Mies, 1991), and a politics we must continue to challenge as we fuse the academic self with the personal; the scientist with the artist; the positivist modes of production with our artistic impulses (Rancière, 2006): the side of us that, as one of my former colleagues pronounced earlier, we “can never crush”.

Inckle's $(2007,2010)$ fictional approach to ethnographic writing provides researchers with creative autonomy to convey personal and lived experience into the academic realm. Gordon's (2008: p. 8) depictions of being haunted demonstrate how experience, both in its narrative recollection and actuality, “draws us affectively, sometimes against our will and always a bit magically, into the structure of feeling of a reality we come to experience, not as cold knowledge, but as a transformative recognition”. By drawing on two ethnographic narratives I wrote one year following my resignation, I intend to tell not just a tale about how a gendered security culture is “taken up, regularized, resisted, contested and transformed” (Järviluoma, Moisala, \& Vilkko, 2003: p. 7), but rather trace the details and memories that shaped how I came to know myself, others and the hospital through the seductions, performances and pitfalls of hegemonic masculinity. The parts and events that comprise these narratives are grim, and only fictional insofar as I have withheld from sharing any real names, dates and times of the events, and it is important to recognize that the quotations I use, at times, may not perfectly represent the actors' words. However, I confess that my memory is still "loud", so in listening to the full volume of these accounts, I hope to provide diverse audiences (i.e. security guards, nursing staff, senior hospital officials, incarcerated mental health patients, scholars and other spectators) with the same vision for social change that still illuminates my pathway towards a "less oppressive way of knowing” (Lather, 1991: p. 95), practicing, accomplishing and performing gender.

More specifically, these narratives demonstrate how the struggle for power is gendered; in particular, the demonstration of hegemonic masculine status entangles the relations, discourses and associated practices of psychiatric ward nurses, patients, and guards - the outcome of which is ward reliance on punitive and restrictive mechanisms of control. By engaging with an embodied, creative methodological practice, I am able to move away from essentialist discourses of gender-or universal categories of representation (Rancière, 2003: p. 199)_that I once subscribed to. This epistemological shift allows me to draw on a queer research posture (Butler, 2006: p. 16) that hunts out the mechanisms through which masculinized violence is distributed, and individualized experiences of gendered embodiment are universally (and thus contradictorily) conveyed. Such nuanced and personal reflections on the self permit me to escape the traditional, hyper-rational, disembodied ways of producing knowledge that do not account for practical, moral, gendered and political processes that are intrinsic to the process of medicalization and incarceration (Appignanesi, 2007). Overall, it is my ambition that this reflexive posture and practice of an embodied methodology that is not oriented around intellectual elitism (Rancière, 2006: p. 55) and the “objectifying scrutiny of [the] academic gaze” (Inckle, 2010: p. 29) will reveal the personal and political processes that are intrinsic to the everyday gendered struggles, frustrations and failures of the psychiatric ward security officer. Although the dialogue I include does not always reflect verbatim statements made by my former colleagues, the names of those involved have been changed to protect interview participants' and other hospital actors' identities, and the times of the emergency calls are only an approximation, I emphasize that the events I divulge are not fabricated. The free form of ethnographic writing with which I engage re-creates, with fewer of the restrictions that often accompany traditional academic writing, a detailed and nuanced, yet accurate snapshot of the hyper-masculine security agents, psychiatric patients and the hegemonic masculine performances that preside over institutional life. Such a profound, reflexive, politicized portrait of the psychiatric ward entrenches emotional spaces for expression within the research process (Dickson-Swift, James, Kippen, \& Liamputtong, 2009), which in turn produces an empathetic catharsis within both the writer and reader -one that is not interrupted by inaccessible language or a theoretical analysis that is limited in terms of accessi- 
bility, to scholars. In short, we must take into consideration that a good story is often simple, nuanced and heartfelt. What is most important, in this case, is that the security stories "reveal something of the self" (Jewkes, 2012: p. 72) for a vast array of audiences "to take it in, and use for themselves" (Coles, 1989: p. 47) so as to contribute to the radical transformation of unjust societies and practices (Guba \& Lincoln, 2005).

Now that I have methodologically situated this research within the reflexive events and autoethnographic literature that steers my critical feminist voice and epistemology, I move to an exploration of the personal and aesthetic politics that moved me towards an embodied, "less oppressive" (Lather, 1991: p. 95) way of understanding gender, men, and the pitfalls of hegemonic masculine performances. Following that discussion, we turn to the ethnographic narratives that are the pinnacle of this masculine tale.

\section{Towards an Embodied Politics and Distribution of the Sensible}

The great majority of the very rich and powerful on planet Earth are men. They compete among each other for more wealth and power, and mobilize workforces of both men and women to do so. There is a good deal of violence on the planet, most of it by men, and a good part of it from armed forces, police and prison systems, overwhelmingly composed of men...Masculinities and femininities are generally constructed around these conditions, and many of the planet's inhabitants accept them without protest. People who violate accepted patterns of masculinity and femininity suffer, and are sometimes killed. (Connell, 2009: pp. 132-133)

I cannot deny the impact such traumas, emotions, and frustrations have had on shaping the direction, intensity, and context of this research. What sustains my personal and political dedication to this work are the gendered politics that operate in my most intimate relationships, decisions and struggles (Connell, 2009: p. 137). For some, gender politics function on such a profound emotional level that the political distinctness and function of our everyday gendered interactions and assessments (West \& Zimmerman, 1987: p. 136) may at first be difficult to perceive. Any person, for example, who seeks care, compassion, and safety may not revolt against institutions of medicine, psychiatry, and psychology if their established objective is to preserve the well being of institutional staff members and patients (Liberman, 2006; Moylan, 2009). As such, the controversy over the imprisonment and restraint of persons seeking, or thought to need, psychiatric "treatment" for the betterment of their health is an ideology I questioned and struggled with throughout my security experience. It is safe to assume that my political ambitions in this research are partially informed by my exposure to death and morbidity ${ }^{6}$, gender subordination, discrimination and harassment within the workplace, and the routine demonstration of physical and chemical patient restraining techniques that I cannot separate from pragmatic or legal definitions of violence (Ashcraft \& Anthony, 2008; Federman, 2012; Szasz, 2010). These experiences appear to me as symbols of the prison, which is an institution that is celebrated for its focus on punishment, control, surveillance and above all else hegemonic masculinity (Acker, 1992; Britton, 1997, 2000; Donaldson, 2001; Evans \& Wallace, 2008; Jewkes, 2005).

It is important to note that while this autoethnographic experience reflects the gradual accumulation of my day-to-day hyper-masculine experiences doing security work that I have since translated into gendered politics, I do not seek to exclude others from entering into a collective pursuit on the grounds that they do not hold the relevant expertise. Rancière (2006: p. 55) claims that "egalitarian writing" is based on the assumption that we all share an equal intellectual capacity to create and interpret knowledge. Not only does this concept of intellectual equality imply that some account of universal experience can be excavated from the most complex and suppressed forms of gender expression and interaction, it goes so far as to challenge the coercive treatment and dominant ways of understanding those we judge to be mentally "unfit” and less intelligible. The gendered experiences I reveal aim to enable wider audiences and spectators to trace their personal affiliation to my accounts in order to facilitate an empathetic and "humane" (Ferrell, 1998: p. 24) understanding of the deeply gendered, aggressive, and certainly at times, disturbing demonstrations of power, control and violence by security guards. Such a messy and intimate connection with readers can render in them a political drive that seeks to reconcile

\footnotetext{
${ }^{6}$ Many security guards I interviewed perceive their job as the "dirty work" of the hospital, that is to say, the grotesque masculine activities and responsibilities that degrade and wound the guard's dignity (see Dick, 2005; Thumala, Goold, \& Loader, 2011). Most participants believe they are assigned the gruelling tasks that other, more "legitimate" healthcare staff such as nurses and personal care assistants would protest completing, including registering cadavers—-both adult and infant-in the morgue, and subsequently releasing them to their designnated funeral homes.
} 
unequal positions and bureaucracies (i.e. security guard and nurse over the psychiatric patient), and posit the humane treatment of persons incarcerated within closed institutions.

Since the concern of my personal politics is to determine which images, languages, words, symbols, gestures and statements and so forth legitimate hegemonic understandings of, and coercive interventions with psychiatric patients, it follows that aesthetics must be inextricably woven into these tensions. A politics of aesthetics, ultimately, places universal conceptions and individual particularities under stress to the extent that a regime may come to contradict itself. Ethnographic narrative writing as a form of political representation must therefore introduce a dissensus between what some construct as authentic, grounded, testable research and what others validate as abstract, unreal, fictional representations of the everyday world, so as to problematize the binary methodological customs and impulses that inhibit us from expressing the transformative "aesthetic core in everything [we] do" (Rancière, 2003: p. 204). Yet to disrupt an institutionalized form of gendered power through this framework would require dissociation from any stable, easily resolvable conceptions of distribution, bureaucracy and domination. Power is often mistakenly attributed to persons who possess marginal or limited abilities to exercise it; in this case, we may consider the subordinated security women and men who are assigned with the less dangerous responsibilities of the job because others do not believe they occupy the necessary gender status that is required to excel within their field. To ameliorate any foreshadowed tensions, I maintain that the personal insights, emotional labourings and other reflexive parts that are expressed in this research all locate power within the gender identities and performances of hospital security agents seeking to achieve hegemonic masculine status and control. Hence, it will be difficult to categorize, explain scientifically, or draw finite conclusions from my emotional outpourings, stuttering thoughts, and confident, yet at times traumatic and unstable expressions of narration (Inckle, 2010: p. 39).

On that note, we now turn to the first of two ethnographic narratives that unfold my hyper-masculine experiences within one closed institution in messy, paradoxical, and at times, bloody fashion. Thematically, the first narrative, "Some of us will pass, others will fail, few will resist", demonstrates how obtaining alpha guard status is not only competitive amongst security members, but access is limited to those who can prove that they are not physically inferior. Often, the assessment of one's physical worthiness is dependent on biology, as opposed to ability and performance. The second narrative, "Follow my lead", emphasizes the militaristic, authoritative and coercive discourses some security officers reproduce in order to achieve gendered status in a stressful, demanding and unforgiving hyper-masculine culture.

\section{Part I-Some of Us Will Pass, Others Will Fail, Few Will Resist ${ }^{7}$}

06:50 hr: Arrive on-site. Receive overnight pass-ons from Security Officers (S/O) ANDREWS and MICHAELS. On-duty with Senior S/O PETERSEN and Emergency Room S/O ERICSON.

I close my evidence notebook and place it inside my protective vest's pocket. I am anal-retentive about updating it. It passes the time.

I ask Ed how his night went. “Anything going on last night?” Really, I am asking him if he got to go to any calls that required his "hands-on" assistance. It's a routine question because it gives the guys a chance to receive admiration for their heroic efforts, exaggerated as they may be.

"Nah, fuck all. But did you see the footage with Alicia Friday night?"

Alicia is a new guard who got hired on at a higher rank than many of us will ever achieve. Most of the guys are pissed off. One, she is a woman. Two, she is a small woman.

“No, I haven't even worked with her yet." It's only her second week here, but I already know a lot about her, or at least I think I do. Many of the guys have spent a great majority of the day evaluating her performance. Up to this point, I've been told she's failed every test. That means she doesn't stand a chance, and I am expected not to give her one.

Ed brings up Friday's surveillance footage from Psych-Emerg. He's no whiz at computers, but this is the first camera we learn to operate, and for the most part the only one we pay attention to. He shows me footage of a male patient lighting a cigarette in front of the nursing station. Involuntary patients do this from time to time because they are restricted from going outside to smoke. For some, the patch isn't enough. After the patient lights his smoke, I watch Jordan, our biggest guard, walk up to the patient and gesture to him to put out the cigarette. When the patient refuses, Jordan grabs it from his wrist, and begins to wrestle with him. Ed points to

\footnotetext{
${ }^{7}$ The real names of the participants, security guards, nurses and other "characters" have been replaced with a pseudonym.
} 
the bottom right of the screen.

"Now watch this!"

I observe Alicia walk into the picture with her hands in her pocket. Excited, Ed covers her waist with his index finger.

"You see that?!"

Confused, Alicia appears like she doesn't know what to do. I then see Adriana, a fifteen-year veteran nurse to Psych-Emerg, walk up to Alicia and point to the patient, her lips moving rapidly. Quickly, Alicia grabs the patient's legs and together, she and Jordan bring the patient back to his bed and place him in four-point restraints. I know what Ed is going to say before he says it.

"Un-fucking-believable. How...the fuck...do they give her the senior position?” Jackson, a part time guard, cuts in.

"Why do you think? It's obvious Brad wants to fuck her, he got her the job." Brad has worked here for over twenty years, and is in charge of hiring the new staff.

"That isn’t right," Ed replies. "I’ve been here four years busting my ass." As the conversation goes on, Jerry, the weekend shift supervisor, finally steps out of his office.

"It's an embarrassment on the department. If a two hundred pound patient loses it and she's my back-up... what the fuck is she gonna do? It's a liability to the hospital.” $* * *$

19:50 hr: Shifts ends. Give pass-ons to S/O JONES and S/O BLUTHERS.

“Anything happen today?” Troy asks me.

"Nothing man, but did you hear about Alicia in Psych-Emerg?”

"Oh yeah, bullshit eh?"

Three weeks later, Alicia resigns.

\section{Part II-Follow My Lead}

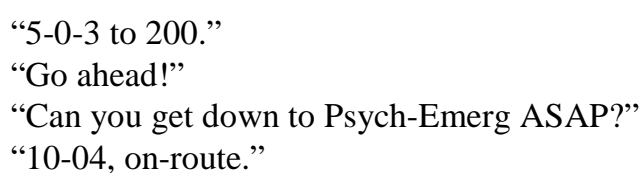

I walk tall alongside Glen to the call. He's not my back-up, I'm his back-up. There's a difference. Glen re-positions his radio on the upper right portion of his uniform sleeve. It clips onto the side of his protective vest. They're not bullet proof, but people think they are. And we don't tell 'em any different.

We reach the elevators on the seventh floor. Five minutes ago, we just finished dealing with a neuro patient who told one of the nurses to fuck off. He doesn't see the need for us to be up there. Deep down, neither do I. But our last words to him are short, swift and frightening: "If we have to come up here again, there will be consequences."

It buys us time to get down to Psych-Emerg, where a "real" call can happen.

I stand beside Glen in the elevator. I wait for him to push the ground floor button. Simultaneously, we pull our notebooks from our vest pocket and scratch in the time and purpose of the call. The cops always tell you in training that documentation saves your ass.

The elevator door opens, and Glen darts out the front door. Controlled, I follow. We hurry to Psych-Emergthere are two sets of doors that require special identification. Without it, there is no getting in —or out. We enter the ward. There are six patient rooms situated alongside each other. The nursing station is positioned in front of the rooms. Here, nurses work quietly behind a transparent barrier that allows them to watch the patients while staying protected from them.

The second I walk through the door, I hear the male patient shout to the male nurse that he's not leaving. Antonio, 5-0-3, is sitting inside the nursing station. Glen motions to Antonio through the barrier that "we're going in”. We take two steps forward, and are interrupted by Jordan's voice, “Glen, don't bother talking to him I've already tried. It's pointless.”

Glen stops. I stop. We wait for Antonio to step outside the nursing station. There are three of us now. We go in together. I am the last to go in the room, standing between Glen and Antonio. The male patient, who I later learn is nineteen, stands in front of us, shaking. Antonio speaks first: 
"You gotta leave buddy."

“I’m not fuckin' leavin'!” The patient replies.

"Well, they're saying you have to so if you don't we're gonna make you.” And in slow motion, the patient's whole body begins to shake. He looks left and right, and then darts towards the space between Antonio and I. Antonio grabs the patient and places him in a headlock. He pulls him towards the bed. Before he crashes on the mattress, Glen dives towards the patient, punching him three times in the area that connects his neck to his head. I make my move and grab the patient's legs as we place him onto his bed. The slow motion ends and I hear the male nurse's voice:

“Just call the fuckin' cops we're having him charged. He doesn't wanna leave-we're having him fuckin' charged."

My attention is quickly drawn back to the patient as Antonio and I press on the back of his knees to prevent him from kicking. Of course, he doesn't kick. With his right arm, Glen presses on his cheek to force his face into the pillow. One eye is exposed, revealing the trail of a tear that has plunged down the side of his face. With his left arm, Glen holds the patient's wrist behind his waist. I watch him apply pressure, and the patient's wrist bends towards his arm. Like a pig, he squeals ${ }^{8}$.

“OK! OK!"

And finally, Glen says something, "Wow I thought you wouldn’t be such a pussy guy there. I guess you're just a pussy guy.”

The crying intensifies. The patient apologizes, and then explains to us that he doesn't want to go back home. I stop looking in the patient's eyes and stare down at the legs that I hold. I relax my grip and hear Glen laugh. I wonder, does he think it's funny or does he think he needs to think it's funny? I guess it doesn't matter either way.

The male nurse comes back into the room. He holds in his hand a bucket where the four-point restraints are kept. The four of us each take one and tie it to the bed. The nurse draws up a sedative and injects it into his bare ass. We then turn him over and place each of his limbs in restraints. The patient doesn't fight back. In my own mind I wish he would. I wish he'd just give us something to justify it all. But I know that isn't how injustice works. There's more to it than the blood that runs from the cut on his nose.

After the patient is restrained and sedated, we sit in the nursing station and write our versions of what happened in our notebooks. Glen is the last to finish. Surprise. We wait here until two male police officers arrive. One asks Antonio what the patient's mental status is. He replies that he just has anger management problems. At this point, Glen informs me that I can go back to the office, so I do. Back at dispatch, my partner, Ed, greets me with enthusiasm.

"That was a gong show!"

I suspect he's jealous he didn't get to participate. Most of the guys prefer not to watch the Psych-Emerg rooms from afar on our surveillance system. His next words, however, confirm what I thought I witnessed:

"It looks like Glen got a few punches in there."

"Yeah, he did." I reply. And that is the last we speak of it.

Eventually, the Security Supervisor enters our office with the two police officers to review the video footage. Appearing satisfied with what they see, the male police officers leave the office. On camera, I watch the police officers escort the patient off hospital property in handcuffs.

I take it we are the heroes since they charge him with assault.

\section{Reflexive Discussion}

Part I illuminates the discrete, collective, complex chain reaction of gender hegemonies and discrimination that underlie some of my most casual exchanges with fellow staff members. I understand how the reproduction of masculinity is facilitated by an onslaught of subtle authority. Even the slightest participation in these exchanges, I learned, allows for criticisms against Alicia's size and apparent "weak" physique to materialize in speech and interaction (West \& Zimmerman, 1987). I am expected, without being asked, to applaud their remarks, overt

\footnotetext{
${ }^{8}$ Coincidentally, this part of the attack corresponds with one filmic representation of a psychiatric ward, One Flew Over The Cuckoo's Nest (Dir. Milos Forman, 1975), where a tough male orderly by the name of Washington (played by Nathan George) throws rebellious patient Randle Patrick McMurphy (played by Jack Nicholson) on the ward floor stomach-down. Washington places Randle’s hands in a wristlock and applies pressure, which in turn causes Randle to scream out in a similar pitch as the nineteen-year old patient I described.
} 
discrimination, and attempts to mock and subordinate her feminine-presenting gender identity. Her fate is pronounced in the end: she is a physical liability on the grounds that she does not hold the capacity-as demonstrated by her reluctance to restrain a patient who is resisting a hospital smoking policy-to dominate, control and if necessary, subdue (Monaghan, 2002; Rabe-Hemp, 2009; Rigakos, 2002) psychiatric patients who are labeled by nursing authorities as aggressive and dangerous.

The images, words, and repeated accounts of gendered discrimination and subordination I read and re-read raise several questions of interest. Does she place her hands in her pocket for comfort? Is she dismayed at the violence that her colleague provoked before she came onto the scene? Is she frightened of the muscular security guard and the disobedient patient? Or is she more scared about what the nurse is commanding her to do? Of course, these haunting questions are irrelevant to men whose primary fear concerns Alicia's ability to live up to the aggressive, intimidating, hegemonic masculine images and demeanors that security agents are expected (by both nursing staff and other guards) to maintain. She is a physical liability, they determine, and nothing else. Without her present, I can sense the injustice of it all. I feel the force of the final blow our superior delivered once all guards had agreed that Alicia is inferior. Each time I read that she quits, I feel a sense of loss. But in that loss, I gain a better sense of my own politics and gender identity. I am reminded of the man I do not wish to be, and I understand the deep consequences and pain that emerge from all forms of gendered discrimination, shaming and subordination. I realize that these gender power relations underlie the discourses and practices security guards draw on to "treat" mentally ill patients.

Perhaps my self-examination at this point reminds some of the moments where "home becomes unfamiliar", and our "bearings on the world lose direction" (Gordon, 2008: p. xvi)—when the ghosts we try to put away in the past reappear in a bold new reality that forces us to reexamine, and potentially transform our identities. In this case, writing about the past signifies the strengthening of my inner voice that calls for social justice, while still forgiving the blood and hyper-masculine events that make life harder for all staff and patients inside the hospital. I read Part II and I am reminded of the countless victims who go unnoticed in incidences such as the one I illustrated in Part I. Subject to a myriad of coercive control mechanisms from all angles of the lunatic asylum (Holmes \& Federman, 2006: p. 17), the patient's restrained body comes to symbolize how institutional power is reconfigured to disperse authority and pain into the widely distributed functions of governmentality (Butler, 2006: p. 72). We are all responsible for exacerbating the dangerousness and recalcitrant identity of the young patient; so surely, many of us might question how circumstances can devolve into restrictions and environments that mirror our darkest institutions. But knowing my own mind and being acquainted with the modernist era of fictional literature, I cannot end a tale, real or unreal, without including a symbol of hope, a symbol of courage, a reminder that our agency as human beings allows us to transgress and overcome horrific, grievous, circumstances. Without a clear, definable authoritative power it becomes difficult to attach responsibility to an individual, or fully realize one's accountability to the depriving conditions, violence and bodily violations of integrity that patients must endure. During our violent struggle, we come to understand the patient not only as "unruly" (Monaghan, 2002) and animal-like in consciousness (Butler, 2006), but also as incapable of engaging in reason or as being defined by us - the authorities and arbiters in determining sanity in the encounter-as reasonable. It was only when I witnessed the tears and felt emotion pouring down the man's cheek that I realized the performative act and fear behind all of our gestures, commands, and established authority. The volume of his cry, the intensity of his pleas, the re-experience of shock as I witnessed him be brutalized-all of these outcries, flashes of memory, and artistic representations of my institutional past destabilize the logic behind the perpetuation of these violent/coercive forms of masculine oppression (Rancière, 2003, 2006). I understand, now, how I became a critical researcher, scholar and artist, but more importantly, I know why I left my uniform behind.

\section{Acknowledgements}

I would like to give a very heartfelt thank you and appreciation to Genevieve Ross, Jennifer Kilty, Nicole Shukin, Kevin Walby, Aaron Devor and my pals at the $28^{\text {th }}$ Annual Qualitative Conference and the $3^{\text {rd }}$ Annual International Crime, Media \& Popular Culture Studies Conference for their support, revisions, and guidance during the difficult and rewarding phases of this research.

\section{Declaration of Conflicting Interests}

The author declared no potential conflicts of interests with respect to the authorship and/or publication of this 
article.

\section{Funding}

This research received no specific grant from any funding agency in the public, commercial, or not-for-profit sectors.

\section{References}

Acker, J. (1990). Hierarchies, Jobs, Bodies: A Theory of Gendered Organizations. Gender \& Society, 4, 139-158. http://dx.doi.org/10.1177/089124390004002002

Acker, J. (1992). Gender Institutions: From Sex Roles to Gendered Institutions. Contemporary Sociology, 21, 565-568. http://dx.doi.org/10.2307/2075528

Appignanesi, L. (2007). Mad, Bad and Sad: Women and the Mind Doctors. New York: W. W. Norton and Company.

Ashcraft, L., \& Anthony, W. (2008). Eliminating Seclusion and Restraint in Recovery Oriented Crisis Services. Psychiatric Services, 59, 1198-1202.

Britton, D. M. (1997). Gendered Organizational Logic: Police and Practice in Men’s and Women’s Prison. Gender \& Society, 11, 796-818. http://dx.doi.org/10.1177/089124397011006005

Britton, D. M. (2000). The Epistemology of the Gendered Organization. Gender \& Society, 14, 418-434. http://dx.doi.org/10.1177/089124300014003004

Butler, J. (2004). Undoing Gender. New York: Routledge.

Butler, J. (2006). Precarious Life: The Powers of Mourning and Violence. London: Verso.

Coles, R. (1989). The Call of Stories: Teaching and the Moral Imagination. Boston, Massachusetts: Houghton Mifflin Company.

Connell, R. W. (1987). Gender and Power: Society, the Person, and Sexual Politics. Oxford, England: Polity Press.

Connell, R.W. (1995). Masculinities. Berkeley: University of California Press.

Connell, R.W. (2009). Gender. Cambridge: Polity Press.

Connell, R. W., \& Messerschmidt, J. W. (2005). Hegemonic Masculinity: Rethinking the Concept. Gender \& Society, 19, 829-859. http://dx.doi.org/10.1177/0891243205278639

Denzin, N. K. (2003). Performance Ethnography Critical Pedagogy and the Cultural Politics of Culture. Thousand Oaks, CA: Sage.

Dick, P. (2005). Dirty Work Designations: How Police Officers Account for Their Use of Coercive Force. Human Relations, 58, 1363-1390. http://dx.doi.org/10.1177/0018726705060242

Dickson-Swift, V., James, E. L., Kippen, S., \& Liamputtong, P. (2009). Researching Sensitive Topics: Qualitative Research as Emotion Work. Qualitative Research, 9, 61-79. http://dx.doi.org/10.1177/1468794108098031

Donaldson, S. D. (2001). A Million Jockers, Punks, and Queens. In D. Sabo, T. A. Kupers, \& W. London (Eds.), Prison Masculinities (pp. 118-126). Philadelphia, PA: Temple University Press.

Doucet, A., \& Mauthner, N. S. (2008). What Can Be Known and How? Narrated Subjects and the Listening Guide. Qualitative Research, 8, 399-409. http://dx.doi.org/10.1177/1468794106093636

Duncanson, C. (2009). Forces for Good? Narratives of Military Masculinity in Peacekeeping Operations. International Feminist Journal of Politics, 11, 63-80. http://dx.doi.org/10.1080/14616740802567808

Evans, T., \& Wallace, P. (2008). A Prison within a Prison? The Masculinity Narratives of Male Prisoners. Men and Masculenities, 10, 484-507. http://dx.doi.org/10.1177/1097184X06291903

Federman, C. (2012). The Mentally Ill and Civil Commitment: Assessing Dangerousness in Law and Psychiatry. In D. Holmes, T. Rudge, A. Perron, \& I. St-Pierre (Eds.), (Re)thinking Violence in Health Care Settings: A Critical Approach (pp. 297-314). Surrey: Ashgate.

Ferrell, J. (1998). Criminological Verstehen: Inside the Immediacy of Crime. In J. Ferrell, \& M. Hamm (Eds.), Ethnography at the Edge (pp. 20-42). Boston: Northeastern University Press.

Fielding, N. (1984). Police Socialization and Police Competence. The British Journal of Sociology, 35, 568-590. http://dx.doi.org/10.2307/590435

Gordon, A. F. (2008). Ghostly Matters: Haunting and the Sociological Imagination. Minneapolis: University of Minnesota Press.

Guba, E. G., \& Lincoln, Y. S. (2005). Paradigmatic Controversies, Contradictions, and Emerging Confluences. In N. Denzin, 
\& Y.S. Lincoln (Eds.), The Sage Handbook of Qualitative Research (pp. 253-291). Thousand Oaks: Sage Publications.

Haggerty, K. D. (2004). Ethics Creep: Governing Social Science Research in the Name of Ethics. Qualitative Sociology, 27, 391-414. http://dx.doi.org/10.1023/B:QUAS.0000049239.15922.a3

Herrera, C. D. (1999). Two Arguments for “Covert Methods” in Social Research. British Journal of Sociology, 50, $331-343$. http://dx.doi.org/10.1080/000713199358770

Holland, K. (2007). The Epistemological Bias of Ethics Review: Constraining Mental Health Research. Qualitative Inquiry, 13, 895-913. http://dx.doi.org/10.1177/1077800407304469

Holmes, D., \& Federman, C. (2006). Organizations as Evil Structures. In T. Mason (Ed.), Forensic Psychiatry: Influences of Evil (pp. 15-30). New Jersey: Humana Press.

Holmes, D., Jacob, J. D., \& Perron, A. (2014). Power and the Psychiatric Apparatus: Repression, Transformation and Assistance. Surrey: Ashgate.

Holmes, D., Rudge, T., Perron, A., \& St-Pierre, I. (2012). Re-Thinking Violence in Healthcare Settings: A Critical Approach. Surrey: Ashgate.

Inckle, K. (2007). Writing on the Body? Thinking through Gendered Embodiment and Marked Flesh. Newcastle-Upon-Tyne: Cambridge Scholars Publishing.

Inckle, K. (2010). Telling Tales? Using Ethnographic Fictions to Speak Embodied Truth. Qualitative Research, 10, 27-47. http://dx.doi.org/10.1177/1468794109348681

Järviluoma, H., Moisala, P., \& Vilkko, A. (2003). Gender and Qualitative Methods. London: Sage Publications.

Jewkes, Y. (2005). Men behind Bars: Doing Masculinity as an Adaptation to Prison. Men and Masculinities, 8, 44-63. http://dx.doi.org/10.1177/1097184X03257452

Jewkes, Y. (2012). Autoethnography and Emotion as Intellectual Resources: Doing Prison Research Differently. Qualitative Inquiry, 18, 63-75. http://dx.doi.org/10.1177/1077800411428942

Johnson, B. (2010). A Few Good Boys: Masculinity at a Military-Style Charter School. Men and Masculinities, 12, 575-596. http://dx.doi.org/10.1177/1097184X09342228

Johnston, M. S., \& Kilty, J. (2014). Power, Control and Coercion: Exploring Hyper-Masculine Performativity by Private Guards in a Psychiatric Ward Setting. In D. Holmes, J. D. Jacob, \& A. Perron (Eds.), Power and the Psychiatric Apparatus: Repression, Transformation and Assistance (pp. 61-90). Surrey: Ashgate.

Lather, P. (1991). Getting smart: Feminist research and pedagogy with/in the postmodern. New York: Routledge.

Liberman, R. P. (2006). Elimination of Seclusion and Restraint: A Reasonable Goal? Psychiatric Services, 57, 576. http://dx.doi.org/10.1176/appi.ps.57.4.576

Librett, M., \& Perrone, D. (2010). Apples and Oranges: Ethnography and the IRB. Qualitative Research, 10, $729-747$. http://dx.doi.org/10.1177/1468794110380548

Mason, T. (2006). Forensic Psychiatry: Influences of Evil. Totowa, New Jersey: Humana Press Inc. http://dx.doi.org/10.1007/978-1-59745-006-5

Mauthner, N., \& Doucet, A. (1997). Reflections on a Voice-Centered Relational Method: Analyzing Maternal and Domestic Voices. In J. Ribbens, \& R. Edwards (Eds.), Feminist Dilemmas in Qualitative Research: Public Knowledge and Private Lives (pp. 119-146). London: Sage.

Mies, M. (1991). Women's Research or Feminist Research? In M. M. Fonow, \& J. A. Cook (Eds.), Beyond Methodology: Feminist Scholarship as Lived Research (pp. 60-84). Bloomington: Indiana University.

Monaghan, L. (2002). Regulating Unruly Bodies: Work Tasks, Conflict and Violence in Britain's Night-Time Economy. British Journal of Sociology, 53, 403-429. http://dx.doi.org/10.1080/0007131022000000572

Moore, D. (1999). Gender Traits and Identities in a Masculine Organization: The Israeli Police Force. Journal of Social Psychology, 139, 49-68. http://dx.doi.org/10.1080/00224549909598361

Morse, C. (1999). Capitalism, Marxism, and the Black Radical Tradition: An Interview with Cedric Robinson. Perspectives on Anarchist Theory, 3, 1.

Moylan, L. B. (2009). Physical Restraint in Acute Care Psychiatry: A Humanistic and Realistic Nursing Approach. Journal of Psychosocial Nursing, 47, 41-47.

Ontario Mental Health Act (1990). R.S.O., Chapter M.7. http://www.search.e-laws.gov.on.ca/en/isysquery/89dfb48a-0d96-492a-90ea28d7e7433cd7z/12/doc/?search=browseStatut es\&context=\#hit1

Phillips, C., \& Earle, R. (2010). Reading Difference Differently? Identity, Epistemology and Prison Ethnography. British Journal of Criminology, 50, 360-378. http://dx.doi.org/10.1093/bjc/azp081

Prokos, A., \& Padavic, I. (2002). There Oughtta Be a Law against Bitches: Masculinity Lesson Inpolice Academy Training. 
Gender, Work \& Organization, 9, 439-459. http://dx.doi.org/10.1111/1468-0432.00168

Rabe-Hemp, C. (2009). Police Women or Police Women? Doing Gender and Police Work. Feminist Criminology, 4, 114-129. http://dx.doi.org/10.1177/1557085108327659

Rancière, J. (2003). Politics and Aesthetics: An Interview (F. Morlock, trans.). Journal of the Theoretical Humanities, 8, 191-210. http://dx.doi.org/10.1080/0969725032000162657

Rancière, J. (2006). The Politics of Aesthetics. London: Continuum International Publishing Group.

Rigakos, G. S. (2002). The New Parapolice: Risk Markets and Commodified Social Control. Toronto: University of Toronto Press.

Shefer, T., \& Mankayi, N. (2007). The (Hetero)Sexualisation of the Military and the Militarization of (Hetero)Sex: Discourses on Male (Hetero)Sexual Practices among a Group of Young Men in the South African Military. Sexualities, 10, 189-207. http://dx.doi.org/10.1177/1363460707075801

Szasz, T. (2010). Coercion as Cure: A Critical History of Psychiatry. New Jersey: Transaction Publishers.

The Huffington Post Alberta (2013). CFB Edmonton Pride Flag: Army Base Flies LGBT Symbol, First in Canada. The Huffington Post Alberta.

http://www.huffingtonpost.ca/2013/06/07/cfb-edmonton-pride-flag n 3404683.html?utm hp ref=mostpopular

Thumala, A., Goold, B., \& Loader, I. (2011). A Tainted Trade? Moral Ambivalence and Legitimation Work in the Private Security Industry. British Journal of Sociology, 62, 283-303. http://dx.doi.org/10.1111/j.1468-4446.2011.01365.x

Walby, K. (2007). On the Social Relations of Research: A Critical Assessment of Institutional Ethnography. Qualitative Inquiry, 13, 1008-1030. http://dx.doi.org/10.1177/1077800407305809

Walby, K. (2009). He Asked Me if I Was looking for Fags...Ottawa’s National Capital Commission Conservation Officers and the Policing of Public Park Sex. Surveillance \& Society, 6, 367-379.

West, C., \& Zimmerman, D. (1987). Doing Gender. Gender \& Society, 1, 125-151. http://dx.doi.org/10.1177/0891243287001002002 